\title{
Housing design that improves the quality of life for post-stroke elderly people living independently
}

\begin{abstract}
Research finds there are greater needs for considered design of the micro environment to improve high-dependency elderly peoples' independence, privacy and overall quality of life. This qualitative review explores the experiences of two representative elderly post-stroke males who require assistance but remain living independently, to identify how design can best support ageing-in-place and enhance quality of life. It finds that to accommodate differences in the level of impairment, it is necessary to provide different types of units or increased flexibility in the design of housing to permit independent living and improve quality of life.
\end{abstract}

Keywords: flexibility, stroke, dwelling, housing
Volume I Issue 4 - 2017

Yukiko Kuboshima, Jacqueline McIntosh

School of Architecture,Victoria University of Wellington, New Zealand

Correspondence: Jacqueline McIntosh, School of Architecture, Victoria University of Wellington, PO Box 600/ 139 Vivian St, Wellington 6001, Wellington, New Zealand,

Email jacqueline.mcintosh@vuw.ac.nz

Received: August 0I, 2017 | Published: August 31, 2017
Abbreviations: QOL, quality of life; IPA, interpretative phenomenological analysis

\section{Introduction}

As people age, they have a greater propensity for impairment and difficulty performing everyday tasks. ${ }^{1,2}$ At some point, typically in their 70 s or later, these experiences will induce them to seek a smaller dwelling in order to continue to live independently. Stroke is one of the major diseases for people aged 65 and over which causes a loss of some functioning and affects their experience of housing. ${ }^{3}$ Research finds that the quality of life (QoL) experienced by elderly people following such an event is significantly reduced, much of which could be ameliorated through greater consideration to housing design. 4,5

For the frail older person, common themes for QoL include; independence, activities and quality of care. ${ }^{6}{ }_{7}$ It has also been suggested that privacy could be at stake, as caregivers enter the home to assist with personal care. ${ }^{8,9}$ This paper explores the design considerations for housing required for the post-stroke elderly who live independently and require assistance from others to maintain QoL.

\section{Method}

This paper examines the lived experience of two representative stroke victims, taken from a larger ethnographic case study of 30 highly-dependent elderly residents and their caregivers in the Wellington region of New Zealand. Using data from a housing provider survey to find typical rental housing for the elderly, then a dependency survey to aid in respondent selection, stroke victims were interviewed and then observed for a full day in their homes. Data were analyzed using Interpretative Phenomenological Analysis (IPA). The personal experiences of two post-stroke elderly men have been examined, the details of which are shown below (Table 1).

Table I Basic information on residents and settings of the selected cases

\begin{tabular}{llll}
\hline & & Case I & Case 2 \\
\hline & Age & 86 & 73 \\
Resident & Male & Two strokes 2.5 years prior, has right & Male \\
& Types of impairment & Stroke I4 years ago, has left hemiplegia. The \\
& Required assistance & None (Supposed to receive supervision in & Bathing, Personal hygiene, Put on/remove \\
& Caregiver visits & 5 days/week & compression stockings
\end{tabular}

Space for independence and activities: shrinking space and increasing importance of sitting space

The features of this type of housing include; the setting of the living unit within an overall complex; common unit types of bedsit and one-bedroom units, a semi-detached or apartment-style dwelling. Some housing providers provide additional social support for residents, such as organizing recreational activities and regular house visits; however, assistance with household tasks and personal care is generally provided by external care providers. Most residents live alone. 
For Resident 1, who had a lower level of impairment, independence meant recovering what he had formerly been able to do and he tried to do as much as possible himself, He used a variety of spaces for every kind of non-sedentary activities, such as cooking in a kitchen and pedalling on an exercise bike and he took advantage of the long corridor of the apartment building for regular walking. Various spaces are required to facilitate independence, including the circulation corridors for exercise.

On the contrary, Resident 2 spent most time in the same sitting space. This space, while allowing him rest in his most comfortable posture and to adjust his leg and back position, also facilitated many activities such as watching TV, reading, eating, seeing outside and taking a nap. He perceived such activities as important, because they 'kept waking him up.' In the design of the space for people with restricted mobility, there should be careful design consideration of the micro environment. The spatial organization should allow the layout of an adjustable armchair and adjacent tables and/or shelves to ensure things are within the reach to facilitate ease of maintaining the space and enhancing control of their environment. Consideration of preferred activities can ensure that sufficient area to accommodate intended use. Space that can accommodate a table as well as an armchair is necessary for elderly with left hemiplegia to do certain activities that require special posture.

\section{Control and privacy: design of the sequential space between interior and exterior}

The sequence of space from the main sitting area to the outside must be designed for access and control. Knowing visitors are coming before they arrive increases the sense of control. The spatial organisation that allows residents to view visitors coming while the resident is seated preferable. For those with limited mobility, the front door should be within sight of the sitting space as well as close enough for the voice to carry through the door. An interphone could be an alternative, but the handset must be within the reach of the sitting space.

Because of privacy concerns that passers-by could look into his unit from very close paths, Resident 1 typically shut the curtains during the daytime, unless it was very sunny. Resident 2 disliked shutting the curtain and kept them open. He did not mind people looking into his unit, but there was no clear sightline to his unit or path nearby where people often passed. In the design of small spaces, there should be greater attention given to the spatial relationship between the interior and exterior, including the placement of windows and curtains with respect to the visibility between the inside and the outside and permitting the enjoyment of sunshine without compromising privacy. There should be enough consideration in the design strategies to meet the conflicting needs for high levels of privacy and other desires such as looking outdoors and welcoming visitors.

\section{Design to improve sense of control: flooring and storage}

Increased consideration of the maintenance and cleaning requirements of floor materials is required for post-stroke elderly people. Resident 2, whose hand shook, often spilt liquids (tea/soup) and didn't like carpet, which stained easily and was never cleaned even by the home-helper. He desired a non-slip resilient floor, which could be cleaned easily. Similarly, the considered placement of shelving of appropriate height and depth for ease of reach for the mobility impaired can improve their sense of control over their space, enabling them to organise and store their belongings.

\section{Increasing privacy needs: design strategies in the private units and the communal space}

While Resident 1 didn't have any privacy concern, Resident 2 had high privacy needs derived from his incontinence. Incontinence is a common problem for many elderly people, the concerns of which can be worsened by restricted mobility. Locating a toilet as close to the sitting space or the bed as possible could address this issue for some; however, a distance 3 meters between these two spaces was insufficient based on the findings of this study. Therefore, for those with severe mobility concerns, accommodation should be made for toileting to occur in the lounge as well as in the bedroom through the use of a commode, or other device. Concerns relating to incontinence also affected his social life as he did not want join activities held in the communal room.

\section{Conclusion}

Rental housing for the elderly provided by local authorities as well as voluntary agencies is typified by relatively small units. In the design of housing there is a greater need for considered design of the micro environment to improve residents' independence, privacy and other aspects important for their QoL. There are differences in the meaning of independence and the degree of privacy required by the level of impairment. There are also differences in the specific design requirements to accommodate individual preferences. Accordingly, it is necessary to provide different types of units that residents can choose from or provide increased flexibility in the design of housing units or complexes to accommodate the diversity in preferences. Alternatively, given that the level and type of impairment may change as people age, a universal design that meets different requirements could best support ageing-in-place and thereby enhance QoL.

\section{Acknowledgements}

None.

\section{Conflict of interest}

The author declares no conflict of interest.

\section{References}

1. http://www.stats.govt.nz/browse_for_stats/health/disabilities/ DisabilitySurvey HOTP2013.aspx

2. The national centre of mental health research. Older adults in New Zealand - Population changes, health, service use and workforce needs. Te Pou, New Zealand: Springer; 2011. p. 1-14.

3. http://www.stroke.org.nz/

4. Leung $\mathrm{M}$, Yu J, Chow $\mathrm{H}$. Impact of indoor facilities management on the quality of life of the elderly in public housing. Facilities. 2016;34(9/10):564-579.

5. Alison $\mathrm{O}$, Kevin M, Judith $\mathrm{T}$, et al. The relationship between building design and residents' quality of life in extra care housing schemes. Health Place. 2013;21:52-64.

6. Tester S, Hubbard G, Downs M, et al. Frailty and institutional life. In: Hennessy CH, Walker A editors. Growing Older: Quality Of Life In Old Age. Maidenhead, UK: Open University Press; 2004. p. 209-224. 
7. Murphy K, Shea EO, Cooney A. Quality of life for older people living in long-stay settings in Ireland. Journal of Clinical Nursing. 2007;16(11):2167-2177.

8. Hale B, Barrett P, Gauld R. The Age of Supported Independence. Springer; 2010. 1331 p.
9. Nord C. Architectural space as a moulding factor of care practices and resident privacy in assisted living. Ageing \& Society. 2011;31(6):934952. 